\title{
Equivalence Scales and Inequality
}

\author{
by \\ Frank Cowell \\ STICERD, London School of Economics and Political Science \\ and \\ Magda Mercader-Prats \\ Universitat Autònoma de Barcelona
}

Contents:

Abstract

1. Introduction

2. Individual Welfare, Inequality, Social Welfare

3. Econometric Equivalence Scales and Inequality

4. Alternative Approaches

5. An Application

6. Conclusion

7. References

No. DARP 27

March 1999
The Toyota Centre Suntory and Toyota International Centres for Economics and Related Disciplines London School of Economics Houghton Street London WC2A 2AE

Tel.: 020-7955 6678

We are grateful to STICERD for facilitating our collaboration and to Tony Atkinson and François Bourguignon for helpful discussions on issues that form the background to this work. Research was partially supported by the ESRC, Grant No.R000235725. 


\begin{abstract}
At the heart of any distributional analysis there is the problem of allowing for differences in people's non-income characteristics. We examine the role of standard equivalence scales in distributional comparisons and the welfare implications of the basis for constructing equivalence scales. We consider the use of alternative approaches that do not require the specification of a single scale and implement one of these in practical comparison of Spain and the UK.
\end{abstract}

Keywords: Inequality, social welfare, equivalence scales.

JEL Nos.: C13, D63.

(C) by the authors. All rights reserved. Short sections of text, not to exceed two paragraphs, may be quoted without explicit permission provided that full credit, including $(\odot$ notice, is given to the source.

Contact address: Professor Frank Cowell, STICERD, London School of Economics and Political Science, Houghton Street, London WC2A 2AE, UK. Email: f.cowell@Ise.ac.uk 


\section{Introduction}

The economic approach to the study of inequality might be caricatured as the comparison of unlike incomes among otherwise similar people. But in practice it is also about the comparison of incomes of unlike persons with unlike circumstances. Except under the most artificial conditions distributional judgments require an appropriate basis for transforming nominal incomes into a "common currency" through which one person's economic position can be meaningfully measured against another's; this basis for interpersonal comparison has the potential to be as important as the choice of a particular 
inequality index in practical applications. In this paper we review the issues at the centre of this problem and examine the practical problems of implementing the economic principles underlying these issues.

The order of attack is as follows. Section 2 examines in outline the main theoretical questions which are commonly addressed in empirical studies: we examine the role for normative judgments in both inequality and welfare comparisons and introduce the concept of an "equivalence scale". Section 3 examines the standard econometric approaches to the estimation of equivalence scales and their limitations in making practical inequality comparisons. Section 4 considers alternative approaches to the problem of interpersonal comparisons in inequality analysis, and Section 5 illustrates the issues in an empirical application. Finally, in section 6, we conclude.

\section{Individual Welfare, Inequality, Social Welfare}

The basic problem is this: people differ in terms of non-income attributes which are considered relevant in assessing income distributions; how should these differences in relevant non-income attributes (or "needs") be taken into account in the assessment of welfare rankings and inequality rankings of income distributions? We begin with a simplified conceptual framework.

\section{Welfare}

The basis of much of applied welfare economics involves the ranking of states in terms of social welfare. If social welfare is founded on individualism then at the back of our minds we have a relationship such as 


$$
\left(u_{1}, u_{2}, \ldots, u_{n}\right) \rightarrow W
$$

where $1, \ldots, n$ index the people in the community, the $u$ s are individual utility levels, and $W$ is social welfare. To implement this we need both a measure of individual utility (measurability assumption), comparable across individuals (interpersonal comparability assumption) and a basis for aggregating individual utilities in a welfare judgment implied in 1.

Since individual utility - representing individual welfare - is intrinsically unobservable, the first step is to model it. Individual welfare is usually assumed to depend on household consumption so that the model of individual utility takes the form:

$$
\left(\mathrm{q}_{1}, \mathrm{q}_{2}, \ldots, \mathrm{q}_{\mathrm{H}}\right) \rightarrow\left(\mathrm{u}_{1}, \mathrm{u}_{2}, \ldots, \mathrm{u}_{\mathrm{n}}\right)
$$

where $1, \ldots, H$ index the households in the community and $\mathbf{q}_{h}$ denotes the vector of goods consumed by household $h$. The precise relationship involved in 2 will also depend upon each household's nonincome attributes $\mathbf{z}_{h}$ which may include personal characteristics (such as age and disability) of its members, as well as household characteristics (such as location). The standard economic approach goes one stage further: it assumes that consumption decisions are made by well-informed, optimising households in a free market at known prices and constrained by money income. In this case 2 can be replaced by the relation:

$$
\left(x_{1}, x_{2}, \ldots, x_{H}\right) \rightarrow\left(u_{1}, u_{2}, \ldots, u_{n}\right)
$$

where $x_{h}$ is the money income of household $h$; of course in less-than-ideal circumstances this logical step is questionable. This provides one simple story to underpin the following type of relationship that is commonly used in distributional assessments: 


$$
\left(x_{1}, x_{2}, \ldots, x_{H}\right) \rightarrow W
$$

although, of course, other theoretical approaches could also be used to rationalise this connection between incomes and welfare.

However, even if we accept this simple story, there some practical difficulties. As equation 3 shows, the unobservability of individual utility leads to a problem of conversion from non-comparable incomes received by households, to comparable welfare imputed to individuals. A standard way of resolving this conversion is to introduce an equivalence scale $e$ that uses information about $\mathbf{z}_{h}$ to convert nominal incomes $x_{h}$ into incomes $y_{h}$ that are comparable across different types of households and are imputed to individual persons

$$
y_{h}=y\left(x_{h}, \mathrm{z}_{\mathrm{h}}\right):=\frac{\mathrm{Xh}_{\mathrm{h}}}{\mathrm{e}\left(\mathrm{x}_{\mathrm{h}}, \mathrm{z}_{\mathrm{h}}\right)} .
$$

So equivalence scales allow one to incorporate individual heterogeneity in the measurement of social welfare, measuring each person's well-being level using a common metric based on equivalent income. These equivalised incomes $y_{h}$ can then be aggregated in a fashion that appropriately takes into account the numbers of persons in households:

$$
W(\mathrm{x} ; \mathrm{z})=\frac{1}{\mathrm{n}} \sum_{\mathrm{h}=1}^{\mathrm{H}} \mathrm{m}_{\mathrm{h}} \phi\left(y\left(x_{h}, \mathrm{z}_{\mathrm{h}}\right)\right)
$$

where $m_{h}$ is the number of persons in households $h$ and $f$ is a social evaluation function with appropriate properties. ${ }^{1}$

${ }^{1}$ Typically we assume that $\mathrm{f}$ is increasing and that it is concave, so that it satisfies the "principle of transfers". The expression 6 assumes that the social welfare function is additive; this is not necessary to make the concept of an equivalence scale operational, but will be needed for developments later in the argument; 6 also assumes that the appropriate specification for welfare (and inequality) rankings is one 


\section{Inequality}

Following the approach of Atkinson (1970) and Kolm (1969, 1976a,b) it is common to suppose that there is a relationship between social welfare on the one hand and inequality $(I)$ and mean income $(\mu)$ on the other:

$$
(I, \mu) \_W .
$$

Using this line of argument 4 and 7 can be taken to imply a relationship between inequality and household incomes that depends crucially upon a model of individual welfare in terms of income and other household characteristics. For example 6 can be used to define an Atkinson-type inequality index $x^{2}$

$$
I_{\mathrm{A}}(\mathrm{x} ; \mathrm{z}):=1-\frac{1}{\mu(y)} \phi^{-1}\left(\sum_{h=1}^{H} m_{h^{\prime}} \phi\left(y\left(x_{h}, \mathrm{z}_{\mathrm{h}}\right)\right)\right)
$$

where

$$
m_{h^{\prime}}:=\frac{m_{h}}{\sum_{k=1}^{H} m_{k}}
$$

in which family or household units are weighted according to the number of individuals in them - see Cowell (1984), Danziger (1978), Ringen (1993), Shorrocks (1995). For an alternative approach see Ebert $(1995,1996)$.

${ }^{2}$ See Atkinson (1970). 
is the normalised weight for household $h$, and

$$
\mu(y):=\sum_{h=1}^{H} m_{h^{\prime}} y\left(x_{h}, \mathrm{z}_{\mathrm{h}}\right) .
$$

is mean equivalised income.

However, although the role of equivalisation in inequality measurement is made clear by the appealingly simple formulation 8 two points should be noted. First the relationship between inequality measures and welfare functions is not unique. ${ }^{3}$ Second, it is not necessary to postulate a welfaretheoretic basis for the formulation of the inequality measure. For example, take the special case of 8 that is usually employed empirically:

$$
I_{\mathrm{A}}^{\varepsilon}(\mathrm{x} ; \mathrm{z}):=1-\left[\sum_{\mathrm{h}=1}^{\mathrm{H}} \mathrm{m}_{\mathrm{h}^{\prime}}\left[\frac{\mathrm{y}\left(\mathrm{x}_{\mathrm{h}}, \mathrm{zh}_{\mathrm{h}}\right)}{\mu(y)}\right]^{1-\varepsilon}\right]^{\frac{1}{1-\varepsilon}},
$$

where $e_{\in}(0, \infty)$ is the inequality-aversion parameter. Welfare-based inequality measures of this type are ordinally equivalent to members of the generalised entropy class:

$$
I_{\mathrm{GE}}^{\alpha}(\mathrm{x} ; \mathrm{z}):=\frac{1}{\alpha^{2}-\alpha}\left[\sum_{\mathrm{h}=1}^{\mathrm{H}} \mathrm{m}_{\mathrm{h}^{\prime}}\left[\frac{\mathrm{y}\left(\mathrm{x}_{\mathrm{h}}, \mathrm{z}_{\mathrm{h}}\right)}{\mu(y)}\right]^{\alpha}-1\right],
$$

where $\mathrm{a}$ is a parameter indicating sensitivity to a particular part of the income distribution. ${ }^{4}$ Clearly

${ }^{3}$ A given welfare function will imply a unique inequality ordering of distributions with a given total income but not, of course, a unique cardinalisation of the inequality ordering. A given inequality ordering of distributions with a given total income does not define a unique welfare ordering.

${ }^{4}$ The more positive (negative) $a$ in 12 is, the more sensitive $I_{\mathrm{E}}$ is to differences at the top (bottom) of the distribution. (Cowell and Kuga, 1981). The GE family includes many of the indices of common use. $I_{\mathrm{E}}$ is the mean logarithmic deviation, $I_{\mathrm{E}}$ is the Theil coefficient, and $I_{\mathrm{E}}$ is half the square of the coefficient of variation. Where the Atkinson index is defined the corresponding ordinally equivalent members of the two classes $I_{\mathrm{E}}$ and $I$ are given by $a$ and $e$ values such that $a=1-e$. For the special 
equivalisation of incomes plays essentially the same role in the forms 11 and 12 , even though the generalised entropy class is not usually derived from the basis of an explicit social-welfare function.

In short, equivalence scales, by providing an interpersonally comparable measure of living standards, play an essential role in the assessment of social welfare and income inequality. Failure to take account of the relationship between nominal and equivalised income can give a biased picture of both inequality and social welfare. ${ }^{5}$ Standard inequality measurement tools requiring the symmetry axiom (general ranking criteria as well as specific ordinal measures) can, and some cases should, be applied to the distribution of equivalised income.

\section{Equivalence Scales in Empirical Applications}

It has become common practice in empirical studies to infer equivalised incomes or equivalence scales using micro-data from household budget surveys. Such surveys collect data at household level and because they usually contain information, not only on household income and expenditure, but also on household non-income characteristics such as household size and composition, they are often used to estimate so-called "econometric" equivalence scales. This sort of scale, based on an appropriate model specification of the way non-income characteristics affect demands within a standard micro-economic framework, may appear to offer a detached "scientific" approach to the formulation of equivalence scales. However it has been understood for some years now that econometric equivalence scales

forms of 11 and 12 where $a=0(e=1)$ and $a=1$ see Cowell (1995).

${ }^{5}$ This may also lead to surprising results: for example Glewwe (1991) shows that poor-to-rich transfers of nominal income could lead to a fall in inequality. 
cannot in general be identified from observed micro-data; ${ }^{6}$ in practice, they are identified by making assumptions that are not ethically neutral, and that may be criticised as arbitrary and controversial. ${ }^{7}$

Since there can be no one "correct" equivalence scale, the recent literature has emphasized that, instead of choosing one particular scale, it might be appropriate to recognise that views may differ on this issue when measuring and comparing social welfare inequality. This flexible approach is similar to that adopted with respect to other aspects of inequality measurement such as the choice of the inequality or poverty index or the definition of a poverty line. ${ }^{8}$ Such an alternative approach might lead to partial rather than complete rankings of income distributions. A prime example of this - the Atkinson-Bourguignon sequential ranking discussed in section 4 below - approaches the problem by means of a class of social welfare functions that incorporate explicit views on social interdependencies between household income and "needs". A second alternative approach to the indeterminacy of the equivalence scale is to examine welfare and inequality comparisons using an appropriate functional form for the equivalence scale with a range of parameter values to represent alternative distinct views on how non-income characteristics affect household "needs". 9 Social welfare or inequality comparisons can be made subject to an agreement on the parametric functional form of the scale.

${ }^{6}$ See the discussion of Pollak and Wales (1979), and Blundell and Lewbel (1991) in the connection with the 'impossibility' result introduced in section 3 below.

${ }^{7}$ As discussed below, equivalence scales based on other sources of information and methodologies are also used in practice but their construction is also open to criticism.

${ }^{8}$ See for instance the contributions of Sen (1973), Atkinson (1970) and Shorrocks (1983).

${ }^{9}$ See the discussion of the Buhmann et al. (1988) type of approach in section 4 below. 


\section{Econometric equivalence scales and inequality}

It is tempting to think that the problem of comparing persons in unlike circumstances can be resolved by careful applied econometrics. Standard terminology - referring to the "cost of children" for example - might suggest that the construction of equivalence scales, which attempt to measure relative welfare differences of individuals belonging to households with different non-income characteristics could be carried out without appeal to normative judgments. Can we delegate the whole matter to econometricians?

\section{An impossibility result}

Let us briefly consider the underlying methodology of determining an equivalence scale in the form of a function such as that in equation 5. Econometric equivalence scales rely on observed household expenditure patterns at a given moment in time. Household demands are seen as choices resulting from a household welfare maximisation, given prices, total household income and non-income characteristics. Let $U\left(\mathbf{q}_{h}, \mathbf{z}_{h}\right)$ be a well-behaved utility function representing household $h$ 's preferences ${ }^{10}$ over private goods $\mathbf{q}_{h}$ conditional on non-income characteristics $\mathbf{z}_{h}$, let $\mathbf{p}$ be the price vector (assumed to be the same for all households) and $x_{h}$ household total income. From this we can define the indirect utility function $V$ and the household's cost or expenditure function $C$, conditional on household characteristics:

$$
\begin{aligned}
& V\left(x_{h}, \mathrm{p}, \mathrm{zh}_{\mathrm{h}}\right)=\max \left\{\mathrm{U}\left(\mathrm{q}_{\mathrm{h}}, \mathrm{zh}_{\mathrm{h}}\right): \mathrm{pq}_{\mathrm{h}} \leq \mathrm{x}_{\mathrm{h}}\right\} \\
& C\left(u_{h}, \mathrm{p}, \mathrm{z}_{\mathrm{h}}\right)=\min \left\{\mathrm{pq}_{\mathrm{h}}: \mathrm{U}\left(\mathrm{q}_{\mathrm{h}}, \mathrm{z}_{\mathrm{h}}\right) \geq \mathrm{u}_{\mathrm{h}}\right\}
\end{aligned}
$$

${ }^{10}$ We make the common (but often unwarranted) assumption that the views of individuals can be represented by a single function for the household in which they live. 
To determine an equivalence scale first denote a "reference-type" household - one with characteristics $\mathbf{z}_{0}$ and income $x_{0}$; this implies a reference utility level:

$$
u_{0}:=V\left(x_{0}, \mathrm{p}, \mathrm{z}_{0}\right)
$$

The equivalence scale of a household with characteristics $\mathbf{z}_{h}$ can then be expressed as the scalar $e_{h}$ which solves the equation

$$
V\left(x_{h}, \mathrm{p}, \mathrm{zh}_{\mathrm{h}}\right)=\mathrm{V}\left(\mathrm{e}_{\mathrm{h}} \mathrm{x}_{0}, \mathrm{p}, \mathrm{z}_{0}\right)
$$

or equivalently as

$$
e_{h}=\frac{C\left(u_{0}, \mathrm{p}, \mathrm{z}_{\mathrm{h}}\right)}{\mathrm{C}\left(\mathrm{u}_{0}, \mathrm{p}, \mathrm{z}_{0}\right)}
$$

Relation 16 means that members of the household with characteristics $\mathbf{z}_{h}$ have the same welfare (utility) level as members of a household of the reference type when the household receives an income $e_{h}$ times the income of the reference household. The relation 17 makes clear the interpretation of the equivalence scale in terms of the "cost of characteristics" index. More generally 16 or 17 can be used to extract the functional relationship defining the equivalence scale $e$ introduced in equation 5. Clearly this relationship will in general depend on $\mathbf{p}$, and $x_{0}$ or $u_{0}$, so an obvious drawback to the approach from the point of view of inequality measurement is that the "rate of exchange" between nominal income and equivalised income depends on prices the reference level of utility and not just on a particular household's non-income attributes.

However there is a deeper problem with drawing social welfare inferences from this approach. The analysis of demand for goods by different household types identifies preferences conditional on household non-income characteristics; but a complete welfare comparison should be based on 
unconditional preferences, defined over the space of income and non-income characteristics - that take into account the direct effect of non-income characteristics on household welfare. ${ }^{11}$ For example the specification of household welfare (utility)

$$
F\left(U\left(\mathrm{q}_{\mathrm{h}}, \mathrm{zh}_{\mathrm{h}}\right), \mathrm{zh}_{\mathrm{h}}\right)
$$

yields the same demand pattern whatever the form of the function $F$; but the form of $F$ can reasonably be expected to be relevant in welfare comparisons of households with, say different needs, and thus will be relevant to inequality comparisons. In general a unique equivalence scale cannot be recovered from expenditure data. This central "impossibility" result suggests a number of ways forward:

- We might consider broad principles that establish relationships between equivalence scales in different economic circumstances without defining a unique scale. ${ }^{12}$

- We might try to establish minimum conditions that permit the identification of a unique equivalence scale. $^{13}$

${ }^{11}$ See Pollak and Wales (1979). As an example of the problem illustrated by 18 consider the situation of a person suffering from a physical disability: this may affect the pattern of his demands relative to the situation he would have been in without the disability; but we may also reasonably suppose that the disability will directly affect the utility level that the person could achieve from any given bundle of goods.

12 Blundell and Lewbel (1991) show that demands for goods provide no information about equivalence scales in a single-price regime, but that demands for goods provide a unique cost function so that "given the true values of equivalence scales in one price regime, Marshallian demands can be used to recover uniquely the true values of all equivalence scales in all other price regimes". An equivalence scale based on demand estimation can be expressed as the product of relative cost-of-living indices, which can be identified from demand data alone, times an arbitrary constant that the researcher implicitly selects by choosing $F$.

${ }^{13}$ Lewbel (1989) and Blackorby and Donaldson $(1991,1993)$ show that if equivalence scales are independent of the base or reference utility level then complete identification of equivalence scales is possible. The problem is that these (and other) conditions are only partially testable with the information available in household budget surveys. See also Blundell (1996) for an overview of the 
- We might use an arbitrary model of individual utility that permits identification of a unique scale.

\section{An explicit utility model}

Let us examine the implications of choosing an arbitrary identification assumption by using the particularly simple Engel model of household expenditure. ${ }^{14}$ The iso-prop model which rationalises Engel's original idea assumes that households are equally well-off when they spend same proportion of their total budget on food. The utility functions that rationalise Engel's original formulation take the form (See Muellbauer 1974)

$$
U\left(\mathrm{q}_{\mathrm{h}}, \mathrm{zh}_{\mathrm{h}}\right)=v\left(\frac{\mathrm{q}_{\mathrm{h}}}{\hat{\mathrm{e}}\left(\mathrm{z}_{\mathrm{h}}\right)}\right)
$$

In practice, the model requires the estimation of Engel curves for food. Adopting the Working-Leser function suggested by Deaton and Muellbauer (1986) and used in many empirical studies, food share can be estimated according to the following equation:

$$
w_{h}=\alpha+\beta \log \left(\frac{x_{h}}{m_{h}}\right)+\sum_{j=1}^{J} \gamma_{j} m_{j h}+\varepsilon
$$

issue.

${ }^{14}$ See for example the argument in Bourguignon (1993). In the Engel model, differences in non-income characteristics are equivalent to equi-proportionate differences in each of the prices, assumption that implies a unique equivalence scale. Other models implying different unconditional preferences have been suggested. For instance in the Barten (1964) model, which also implies a unique commodity specific equivalence scale structure, changes in family composition act as to modify "equivalent commodities" and "equivalent prices". 
where $j=1, \ldots, J$ are household types, $w_{h}$ is the food share of the household, $m_{h}$ is household size, $m_{h j}$ is the number of members of type $j, x_{h}$ is total income, for household $h=1,2, \ldots, H$, and $a, \beta$ and $?_{j}$ are the parameters to be estimated.

However, we should not suppose that the specification of an explicit utility model will completely resolve the ambiguity raised in our discussion of the "impossibility result". To see this, consider the Engel model further. The number of equivalent adults in $h$, obtained by equating the estimated budget food-share for household $h$ with that for the reference household (0), takes the form:

$$
e_{h}=\frac{m_{h}}{m_{0}} \exp \left(\frac{1}{\beta} \sum_{j=1}^{J} \gamma_{j}\left[m_{j h}-m_{j 0}\right]\right)
$$

An extra member of type $j$ in household $h$, increases $e_{h}$ by a factor which depends positively on $?_{j}$ - the specific effect of household members $j$ on the household food share - and negatively on household size:

$$
\frac{1}{e_{h}} \frac{\partial e_{h}}{\partial m_{j h}}=\frac{1}{m_{h}}+\frac{\gamma_{j}}{\beta}
$$

The paradoxes that can be obtained using this rule are easy to find in practice. Suppose for example we distinguish household types according to the sex of their children in the estimation of equation 20 which is the practice in some empirical applications. ${ }^{15}$ Suppose further that the data reveal that, at a given income level, a typical couple with a female child is better off than a typical couple with a male child: ${ }^{16}$ would it not be more appropriate, from a social-welfare point of view, to treat these two households as being equally well-off? The same kind of argument could apply if other characteristics

\footnotetext{
${ }^{15}$ See for instance Bosch (1990).

${ }^{16}$ This is the case with the data from Spain discussed in section 5 below.
} 
such as race or marital status of the household head were included in equation (5). In short the apparently attractive simplicity of the explicit Engel model approach does not provide a magic bullet for the derivation of equivalence scales in practical inequality comparisons: we still need to introduce explicit welfare judgments based on family circumstances. ${ }^{17}$

\section{Other problems}

There may be sources of difficulty and disagreement about the choice of equivalence scale other than the problems raised by the impossibility result in the establishment of a unique equivalence scale. These relate principally to the nature of the underlying economic model, both in respect of its detailed formal specification and in terms of the welfare information that it is considered legitimate to extract from observables.

First consider the problem of the formal specification of the demand model. This not just an arid technicality, for it is evident that the econometrically estimated equivalence scales and inequality comparisons may be sensitive to the choice of an specific functional form of the demand system. Murthi (1994) shows that the precise form in which non-income characteristics enter demand functions requires particular attention. ${ }^{18}$ There is also the practical difficulty of extending the basic

${ }^{17}$ In the words of Bourguignon (1993): "Même si l'argument de Engel a quelque chose de séduisant il est incomplet. D'autres conditions doivent être satisfaites pour que les comportements de consommation traduisent des différences de bien-être. Reste encore a déterminer ces conditions." (p.8).

${ }^{18}$ In the context of Sri Lankan data she concludes that "the size of the estimated scales appears to be related to the parametric form of the Engel curve" - Murthi (1994, p.182). 
expenditure model which refers to market goods to models that also include the effect of non-market time on welfare. Other than the problems derived from the non-linearity of the budget constraint (Apps and Savage, 1989), there is the problem of the measure leisure itself used (typically measured as non-market time). Furthermore, because the basic model is static, it does not consider the effects of characteristics on intertemporal consumption patterns. Moreover, the basic model also ignores the role of social conditions in generating behavioural differences by sex for example (See Apps, 1994). The sex variable may appear as relevant in the social evaluation if for instance women (because of their sex) are seen as being institutionally constrained on their lifetime income.

Second, actual expenditure patterns may be a poor guide to the fundamental welfare status of households and individuals. This issue goes further than just whether it is appropriate to use a current variable as to proxy a long-run concept: for even if we suppose it possible to set aside the Pollak-Wales difficulty and to recover "true" unconditional preferences on commodity demands there is a deeper question of the distinction between need and choice in the imputation of welfare. In some cases an attribute which appears to be a "need" from an ex post viewpoint may be properly seen as a matter of choice ex ante. ${ }^{19}$ Furthermore it is arguable that even under idealised conditions reliance on observed expenditure levels alone in assessing household welfare may be also subject of controversy. ${ }^{20}$

${ }^{19}$ For example, on the assumption of perfect fertility control, the number of children in the household might be regarded as a matter of choice by the household. So, from the ex ante viewpoint, having children would not be regarded as a "need" any more than a condition induced by one of the commodities consumed by the household. However in practice current fertility decisions may be based on biased expectations about future income, prices, household stability, and since fertility decisions are irreversible, social evaluations ex post may want to take such information failures.

${ }^{20}$ See the arguments given by Fisher (1987) and Coulter et al. (1992a). 
In sum, the choice of a particular equivalence scale to take account of needs-differences in inequality comparisons is subject to a number of fundamental difficulties, and cannot be independent of explicit value judgement. Although we have focused upon the econometric approach in order to explain why this is so similar difficulties might be expected to arise in connection with other approaches ${ }^{21}$ and each approach may introduce its own source of hidden value judgment. For example subjective scales are based on individuals' assessments about their own well-being, and budget expert scales rely on expert judgements (although they may also take into account information on household expenditure). There may even be a systematic relationship between the information-source used for the equivalence scale and the size elasticity of needs, with econometric equivalence scales being more generous to household size than subjective scales, the budget expert lying in between. ${ }^{22}$

The implication of this is that inequality measurement conclusions based on a single equivalence scale are likely to be open to controversy and may partially conceal loaded value judgments. If views about the equivalence scale parameter differ, can inequality be measured at all?

\section{Alternative Approaches}

As we have pointed out, since the construction of an equivalence scale involves ethically non-neutral choices, these should be recognised when measuring and comparing inequality levels in the same way this is done in other aspects of income distribution assessments. In this section we discuss two

\footnotetext{
${ }^{21}$ See Coulter et al. (1992a) for a review of these.

${ }^{22}$ See Buhmann et al. (1988) for details.
} 
alternative methods that have been suggested on both theoretical and practical grounds to deal with the indeterminacy of the social equivalence scale.

\section{The Atkinson-Bourguignon dominance approach}

The first of these less informationally demanding methods was introduced by Atkinson and Bourguignon (1987). Assume that the population can be clearly divided into $G$ different categories that can be unambiguously ranked according to needs. ${ }^{23}$ The persons in any household are deemed to be in a particular need category $g$ (where $1 \leq g \leq G$ ) on the basis of the non-income attributes of the household of which they are members:

$$
g=\Gamma\left(\mathrm{z}_{\mathrm{h}}\right),
$$

where $G$ is an agreed needs-categorisation function. If we adopt the individualistic welfare approach outlined in section 2 the evaluation of household incomes will need to be weighted by the number of members in the household $m_{h}$, and so then social preferences may be represented by means of an additive social welfare function of the form:

$$
W_{\mathrm{AB}}(\mathrm{x} ; \mathrm{z})=\frac{1}{\mathrm{n}} \sum_{\mathrm{h}=1}^{\mathrm{H}} \mathrm{m}_{\mathrm{h}} \Phi\left(x_{h}, \Gamma\left(\mathrm{zh}_{\mathrm{h}}\right)\right),
$$

where $F$ is the social evaluation of a household's (unadjusted) income $x$ conditional upon a particular needs categorisation. Expression 24 can be written

$$
W_{\mathrm{AB}}(\mathrm{x} ; \mathrm{z})=\sum_{\mathrm{g}=1}^{\mathrm{G}} \pi_{\mathrm{g}}\left[\frac{1}{\mathrm{n}_{\mathrm{g}}} \sum_{\mathrm{h} \in \mathrm{N}_{\mathrm{g}}} \mathrm{m}_{\mathrm{h}} \Phi\left(x_{h^{\prime}} g\right)\right]
$$

${ }^{23}$ Atkinson (1992) suggests a generalisation of this criteria when there is no agreement on the ranking of households by type. 
where $N_{g}$ denotes the set of individuals in needs category $g$ according to $G$ in $23, n_{g}:=\# N_{g}$ and $p_{g}:=n_{g} / n$. The ranking of categories $1, \ldots, G$ by needs is interpreted as a requirement that the marginal social evaluation of income, or "welfare weight" ${ }^{24}$, be positive and increasing with the degree of need:

$$
\Phi_{x}\left(x_{h}, g\right)>\Phi_{x}\left(x_{h}, g-1\right)>0, \forall g=2, \ldots, G,
$$

where the subscript denotes the partial derivative. The principle of transfers requires that the welfare weight be decreasing for each needs category:

$$
\Phi_{x x}\left(x_{h}, g\right)<0 \quad \forall g=1, \ldots, G .
$$

For all social evaluation functions $F$ satisfying these assumptions, a set of dominance conditions can be established under which it can be said that one distribution unambiguously yields higher social welfare than another. The sequential dominance conditions (Atkinson and Bourguignon, 1987) are a generalisation of traditional Lorenz dominance conditions and can be summarised as follows. Let the components of income vectors be labelled so that $x_{1} \leq x_{2} \leq \ldots \leq x_{n}$ and let - denote the generalised-Lorenz dominance relation. ${ }^{25}$ Also let us use $\mathbf{x}$ to denote the subvector of $\mathbf{x}$ that consists of just the incomes of all persons in the bottom $g$ needs categories - i.e. those persons in $N_{1} \cup N_{2} \ldots \cup N_{g}$. Then distribution $(\mathbf{x}, \mathbf{z})$ represents higher social welfare than distribution $\left(\mathbf{x}^{\prime}, \mathbf{z}\right)$ if $\mathbf{x}_{-} \mathbf{x}$ for all $g$, with strict dominance for at least one value of $g$.

\footnotetext{
${ }^{24}$ See Cowell (1995) page 37.

${ }^{25}$ The generalised Lorenz dominance relation $\mathbf{x}_{-} \mathbf{x}^{\prime}$ means that Install Equation Editor and doubleclick here to view equation. and $\mathbf{x}^{\prime}{ }_{-} \mathbf{x}$ - see Shorrocks (1983).
} 


\section{Comparing the Atkinson-Bourguignon and equivalence scale approaches}

Let us look again at the equivalence scale approach in the context of the social-welfare function. Using the categorisation function 23 we can rearrange the explicit welfare function equation 6 thus:

$$
W(\mathrm{x} ; \mathrm{z})=\sum_{\mathrm{g}=1}^{\mathrm{G}} \pi_{\mathrm{g}}\left[\frac{1}{\mathrm{n}_{\mathrm{g}}} \sum_{\mathrm{h} \in \mathrm{N}_{\mathrm{g}}} \mathrm{m}_{\mathrm{h}} \phi\left(\frac{x_{h}}{e\left(x_{h}, \mathrm{zh}_{\mathrm{h}}\right)}\right)\right]
$$

The contrast between $\mathrm{f}(x / e(x, \mathbf{z}))$ in 6 and 28 and $\mathrm{F}(x, G(\mathbf{z}))$ in 25 is illuminating. Whereas the first presupposes an exact functional form for representing needs in order to convert from nominal income to equivalised income, to implement the second we need only an agreed needs-categorization function and some weak ordering properties on the evaluation function conditional on needs. Under the Atkinson-Bourguignon approach, assumptions imposed on the social evaluation function $\mathrm{F}(., g)$ take account of the uncertainty of the income inequality aversion parameter as well as of the uncertainty on the assessment of needs and its interaction between income inequality, and this is precisely one of the strengths of the method. However, weaker conditions on the social evaluation function conditional on needs are not without cost. The possible disadvantage of the Atkinson-Bourguignon method is that it leads to partial rather than complete rankings of income distributions. Moreover, the use of these dominance results is restricted to cases where the marginal distribution of needs is fixed in the distributions being compared: this restriction makes it more suited to situations such as looking at the redistributive effect of taxes and benefits at a given time period than intertemporal or inter-country comparisons $^{26}$.

${ }^{26}$ See for example Hugounenq and Sastre-Descals (1991 and 1993). The extension of this approach to the case where the distribution of needs differs between the two groups being compared is considered by Lambert and Jenkins (1993). 


\section{Social dominance with respect to a parametric class of equivalence scales}

The second alternative approach is to use a parametrised family of equivalence scales. Families of parametric equivalence scales are defined in terms of functions of a few relevant non-income characteristics, with parameters summarising how needs change as non-income characteristics are modified. In general, the parametric form can be written thus:

$$
e_{h}=\tilde{e}\left(\mathrm{Zh}, \mathrm{Xh}_{\mathrm{h}} ; \theta\right)
$$

where ? is a vector of parameters.

Given a particular parametric form 29 and a set of admissible parameter values $\mathrm{T}$ a parametricclass dominance relationship can be specified. Analogous to the use of simple ranking tools for distributional comparisons (such as the Lorenz curve) rather than a specific inequality measure (such as a particular index from the Atkinson class), one could use the functional form to generate a distributional ranking for all $? \in \mathrm{T}$, rather than taking just one equivalence scale for a particular value of ? . We may take the implied welfare function for the approach using a parametric class, namely

$$
W_{\mathrm{PC}}(\mathrm{x} ; \mathrm{z})=\frac{1}{\mathrm{n}} \sum_{\mathrm{h}=1}^{\mathrm{H}} \mathrm{m}_{\mathrm{h}} \phi\left(\frac{x_{h}}{\tilde{e}\left(\mathrm{z}_{\mathrm{h}}, \mathrm{x}_{\mathrm{h}} ; \theta\right)}\right),
$$

If $W_{\mathrm{PC}}\left(\mathbf{x}^{\prime}, \mathbf{z}^{\prime}\right) \geq W_{\mathrm{PC}}(\mathbf{x}, \mathbf{z})$ for all admissible equivalence-scale parameter values $? \in \mathrm{T}$ then it is clearly appropriate to claim that $\left(\mathbf{x}^{\prime}, \mathbf{z}^{\prime}\right)$ dominates $(\mathbf{x}, \mathbf{z})$ conditional on the functional form e. Once again the dominance criteria could be applied in inequality terms: an appropriate inequality index is defined for every $W_{\mathrm{PC}}$ of the form 30 ; inequality can then be computed for all $? \in \mathrm{T}$ to check the sensitivity of 
inequality measurement estimates to the choice of parameter. Of course, as in the AtkinsonBourguignon approach, the social dominance condition with respect to a parametric class of equivalence scale may lead to partial rather than complete ranking of income distribution.

However there are two major issues raised by the specification 29 which remain open, namely the choice of functional form $\mathrm{e}$, and the appropriate selection of $? \in \mathrm{T}$. One method of determining $\mathrm{e}$ would be to adopt a particular functional form for the demand system which will imply a functional restriction on the equivalence scale formula; but in view of the theoretical and practical problems noted in section 3, alternative approaches to the determination of the functional form should be considered. These alternatives include approximations to equivalence scales used in determining relative rates of income support for different household types and those that are motivated principally by a concern for mathematical tractability in modelling. The calibration of a parametric scale - the choice of ? value could be by personal subjective judgment, or by appeal to other evidence of social values. ${ }^{27}$ Whatever the intellectual basis for choosing the functional form e and the admissible set of parameters $\mathrm{T}$ it is clearly advantageous that the parametric equivalence scale should permit representation a wide range of value judgements if consensus on welfare comparisons is to be achieved. ${ }^{28}$

Let us illustrate the approach for a particularly simple and commonly-used functional form that suggested by Buhmann et al. (1988). ${ }^{29}$ Here $e_{h}$, the number of equivalent adults in household $h$,

${ }^{27}$ For example, using the parametric form introduced in 31 below, Rainwater (1994) discusses the use of survey evidence on living standards to calibrate a parametric $s=0.33$.

${ }^{28}$ Duclos and Mercader (1994) use a number of parametric forms to estimate the OECD and McClements scales - see their Table 1, and Figures 1 and 2 for an assessment of the suitability of a particular parametric functional forms.

${ }^{29}$ This parametric form is used in many recent empirical studies. See for instance Atkinson et al. 
depends only on household size, and the vector of parameters ? are reduced to a single parameter $s$ summarising the elasticity of needs with respect to household size, $m_{h}$ :

$$
e_{h}=m_{h}^{s}, \quad \forall s \in[0,1] .
$$

The larger is the value of the constant $s$, the more responsive is the scale to family size: adopting the fiction that household size is a continuous variable, if household size increases by 1 per cent, needs are increased by $s$ per cent. Two limiting cases are of special interest: when $s=0$ the scale takes no account of needs, and when $s=131$ yields the simple per capita equivalence scale.

For the scale 31 an inequality measure analogous to 8 can be defined as:

$$
I_{\mathrm{A}}^{\mathrm{s}}(\mathrm{x} ; \mathrm{z}):=1-\frac{1}{\mu(y)} \phi^{-1}\left(\sum_{h=1}^{H} m_{h^{\prime}} \phi\left(\frac{x_{h}}{m_{h}^{s}}\right)\right)
$$

Suppose that there is agreement that inequality is represented by 32 for a particular evaluation function f and that society considers needs to be well represented by the parametric form given in equation 31 , but that there is no agreement on the particular value of $s$. Then inequality is unambiguously greater (or no lower) in distribution $(\mathbf{x}, \mathbf{z})$ than in distribution $\left(\mathbf{x}^{\prime}, \mathbf{z}^{\prime}\right)$ if and only if

$$
I_{\mathrm{A}}^{\mathrm{s}}(\mathrm{x} ; \mathrm{z}) \geq \mathrm{I}_{\mathrm{A}}^{\mathrm{s}}\left(\mathrm{x}^{\prime} ; \mathrm{z}^{\prime}\right) \quad \forall \mathrm{s} \in[0,1]
$$

It can be easily seen that the parametric approach is also less informationally demanding than the single equivalence scale framework. For a particular parameter value, the form 30 is seen to be as informational demanding as 6: they both presuppose an exact functional form for representing needs in

(1993a,b), Mercader (1993), Rodrigues (1993). The application of this to the construction of household-type-specific poverty lines in the problem of poverty rankings is discussed by Lanjouw and Ravallion (1995). 
order to convert from nominal income to equivalised income. But the form 30 is weaker if the parameter $s$ is allowed to vary over $[0,1]$.

Finally, let us note that the form 31 is obviously not the only useful parametric class that can be envisaged, nor is it ideal in every respect - its extreme simplicity means that it fails to take into account differences in household composition. Simple, empirically implementable generalisations are available. For example we might consider a two-parameter form that allows for the distinction of households according to their number of adults, $A_{h}$, and children, $K_{h}$, in the following way: ${ }^{30}$

$$
e_{h}=\left[A_{h}+c K_{h}\right]^{s} \forall s \in[0,1], \forall c \in[0,1]
$$

\section{An Application}

Let us use the foregoing analysis to examine a simple two-country distributional comparison. We consider the practical problem of comparing income inequality in Spain and the UK when two "degrees of freedom" are left open: there is no single pre-specified value of the equivalence scale, and no single pre-specified inequality index.

To accomplish this we use micro data on disposable income for households in Spain 1980 and UK $1979,{ }^{31}$ and apply the general parametric form of the equivalence scale 34 and $I_{\mathrm{E}}$, the Generalised

${ }^{30}$ See for instance, Cutler and Katz (1992). The comparison of one- and two-parameter forms is considered by Banks and Johnson (1994) and Jenkins and Cowell (1994) highlighting the relevance of the particular form chosen.

${ }^{31}$ The UK data are taken from the 1979 Households Below Average Income survey which contains 6706 households and the Spanish data is a random subsample of 8053 households from the Spanish Household Budget Survey 1980-81 Encuesta de Presupuestos Familiares. Samples are truncated to 
Entropy family of inequality indices 12 . This enables us to explore the interaction between the choice of the scale parameter and social judgements about the sensitivity of the inequality index.

\section{Table 1: GE Index for Spain and UK. Buhmann et al. Equivalence Scale}

\begin{tabular}{|c|c|c|c|c|c|c|c|}
\hline$s$ & 0.0 & 0.2 & 0.4 & 0.5 & 0.6 & 0.8 & 1.0 \\
\hline$a$ & \multicolumn{7}{|c|}{ Spain } \\
\hline 2 & 0.280 & 0.268 & 0.264 & 0.266 & 0.270 & 0.286 & 0.316 \\
\hline 1 & 0.206 & 0.196 & 0.193 & 0.193 & 0.196 & 0.206 & 0.225 \\
\hline 0 & 0.208 & 0.197 & 0.192 & 0.192 & 0.194 & 0.203 & 0.221 \\
\hline-1 & 0.316 & 0.290 & 0.278 & 0.277 & 0.279 & 0.294 & 0.322 \\
\hline$a$ & \multicolumn{7}{|c|}{ UK } \\
\hline 2 & 0.136 & 0.136 & 0.152 & 0.167 & 0.187 & 0.245 & 0.329 \\
\hline 1 & 0.116 & 0.118 & 0.131 & 0.142 & 0.157 & 0.196 & 0.249 \\
\hline 0 & 0.115 & 0.117 & 0.131 & 0.141 & 0.155 & 0.192 & 0.242 \\
\hline-1 & 0.138 & 0.142 & 0.159 & 0.173 & 0.191 & 0.239 & 0.308 \\
\hline
\end{tabular}

1 presents the UK and Spanish estimates of the GE inequality indices for different values of the parameter $s$ given $c=1,{ }^{32}$ and 2 repeats the exercise for the case $c=0.5$. Notice that for all the a-values considered, inequality estimates in the UK appear to be an almost monotonic increasing function of $s$, for both $c$ values, whereas in Spain they show the commonly found U-shape pattern in $s$ (See also 0), and that the UK inequality estimates are much more sensitive to changes in $s$ (the GE more than

remove observations with zero incomes resulting in a final sample of 8037 . and 6692 observations for each country respectively. The income definition is taken to be household disposable income defined as including all main components of regular income - earnings, self-employment income, state and social security benefits and investment income, and is computed after the deduction of direct personal taxes and social security contributions. Income is considered before housing costs. No attempt is made to take account of income and kind or to impute income on assets such as owner-occupied houses. Household population is weighted to give the distribution by individuals, this is, each household is weighted by its number of members.

${ }^{32}$ Notice that for $c=1$ equation 34 is equivalent to equation 31. 
doubles when $s$ moves from 0 to 1) than those for Spain. The reasons for these differences can be explained in terms of dissimilarities in the joint distribution of income and family size (and composition) in the two countries.

Table 2: GE Index for Spain and UK. Cutler-Katz Equivalence Scale ( $c=0.5)$

\begin{tabular}{|c|c|c|c|c|c|c|c|}
\hline$s$ & 0.0 & 0.2 & 0.4 & 0.5 & 0.6 & 0.8 & 1.0 \\
\hline a & \multicolumn{7}{|c|}{ Spain } \\
\hline 2 & 0.280 & 0.270 & 0.269 & 0.272 & 0.276 & 0.292 & 0.317 \\
\hline 1 & 0.206 & 0.196 & 0.192 & 0.192 & 0.194 & 0.202 & 0.215 \\
\hline 0 & 0.208 & 0.197 & 0.191 & 0.190 & 0.191 & 0.197 & 0.209 \\
\hline-1 & 0.316 & 0.292 & 0.279 & 0.276 & 0.277 & 0.285 & 0.305 \\
\hline a & \multicolumn{7}{|c|}{ UK } \\
\hline 2 & 0.136 & 0.135 & 0.146 & 0.156 & 0.170 & 0.210 & 0.270 \\
\hline 1 & 0.116 & 0.117 & 0.125 & 0.133 & 0.143 & 0.171 & 0.210 \\
\hline 0 & 0.115 & 0.116 & 0.125 & 0.132 & 0.142 & 0.168 & 0.203 \\
\hline-1 & 0.138 & 0.140 & 0.151 & 0.161 & 0.173 & 0.206 & 0.252 \\
\hline
\end{tabular}

Focus first on the case $c=1$ (1). The impact of increases in $s$ on measured inequality can be decomposed into an equalising "concentration" effect and a "re-ranking" effect. Since unadjusted income and family size tend to positively correlated in practice, increasing $s$ means that equivalent income for households above average size is likely to fall by more than equivalent income for households below average size as long as $s$ is sufficiently small, and this is an equalizing effect. The same process may change rankings in the equivalent income distribution and this effect may work in the opposite direction. ${ }^{33}$ It is easy to illustrate this for $I_{\mathrm{E}}$, for which:

\footnotetext{
${ }^{33}$ See Coulter et al $1992 \mathrm{~b}$.
} 


$$
\frac{\partial I_{\mathrm{GE}}^{0}}{\partial \mathrm{s}}=-\frac{\operatorname{cov}(\mathrm{y}, \log (\mathrm{m}))}{\mu(\mathrm{y})}
$$

$$
-\frac{\operatorname{cov}(\mathrm{x}, \log (\mathrm{m}))}{\mu(\mathrm{x})}-\mathrm{s} \operatorname{var}(\log (\mathrm{m}))
$$

where, as before, $x$ denotes unadjusted income. Given the observed positive correlation between unadjusted incomes and household size we expect that the equivalent income covariance will be positive for $s$ near zero, but negative for $s$ near one. 3 shows that this is expectation is borne out for both countries although they exhibit differences between them in the detail: in the UK the equivalent income covariance becomes negative as soon as $s$ increases above zero, whereas in Spain, it is positive up to intermediate values of $s$; furthermore the covariance in the UK is everywhere less than in Spain. As a result of these differences, in Spain the equalising effect of increasing $s$ dominates up to intermediate values of $s$, after which it is outweighed by the re-ranking effect while in the UK, the reranking effect appears to dominate over almost the whole range of $s$ values. ${ }^{34}$

It is clear that this type of dissimilarity between countries can have important implications for quantitative comparisons of income distributions. For example, given a specific inequality measure, it is possible to draw a wide range of alternative conclusions conditional on the sensitivity parameter $s$ used in the equivalisation procedure: using $I_{\mathrm{E}}$ in 1 we could conclude that inequality in Spain is eighty percent higher than in the UK (when $s=0$ ), or that inequality is nine percent higher in the UK (when

${ }^{34}$ For a contrasting view where the UK data are based upon the Family Expenditure Survey and where the focus is upon the sensitivity of poverty comparisons (rather than inequality) see Duclos and Mercader (1994). 
$s=1)^{35}$

It is clear too that there is no distributional dominance over the entire range of parameters $(\mathrm{a}, s)$. For low and medium values of the sensitivity parameter $s$ Spain is unambigously more unequal than the UK; for $s$ close to 1 the Lorenz curves of the two distributions intersect. An alternative way of looking at the same point is to note that if the inequality index is very bottom-sensitive $(a=-1)$ the UK income distribution is unambiguously more unequal than the income distribution in Spain for all values of $s$, but that no such dominance result emerges for the other values of the distributionsensitivity parameter a reported in 1: plotting inequality as a function of $s$ there is an intersection at an $s$ value of around 0.8 .

Table 3: Covariance term $\operatorname{cov}(y, \log (m)) / \mu(y)$

\begin{tabular}{lrrrrrrr}
\hline \hline & & & & & & & \\
$S$ & 0.0 & 0.2 & 0.4 & 0.5 & 0.6 & 0.8 & 1.0 \\
Spain & 0.075 & 0.042 & 0.007 & -0.011 & -0.029 & -0.068 & -0.108 \\
UK & 0.016 & -0.039 & -0.095 & -0.124 & -0.154 & -0.215 & -0.278
\end{tabular}

Finally, consider the role of the child-weight parameter $c$ in the inequality comparison. It is evident from $\mathrm{d} 2$ that if $c$ is reduced from 1 to 0.5 , measured inequality will be reduced in both countries, but by more in the case of the UK. This has a particularly interesting impact on comparisons of $I_{\mathrm{E}}$ as illustrated in 0 : a distributional indeterminacy in the case of the simple Buhmann et al. equivalence scale (left-hand panel) becomes one of clear dominance (right-hand panel). How the composition of the family is incorporated in the equivalisation process is important as well as the size of

35 This conclusion survives under alternative cardinalisations. For example $I_{\mathrm{E}}$ equivalent to the Atkinson index $I$ : using this index we find that the possible conclusions from an inequality comparison range from $73 \%$ higher for Spain $(s=0)$ to 8 percent higher for UK $(s=1)$. 
the family.
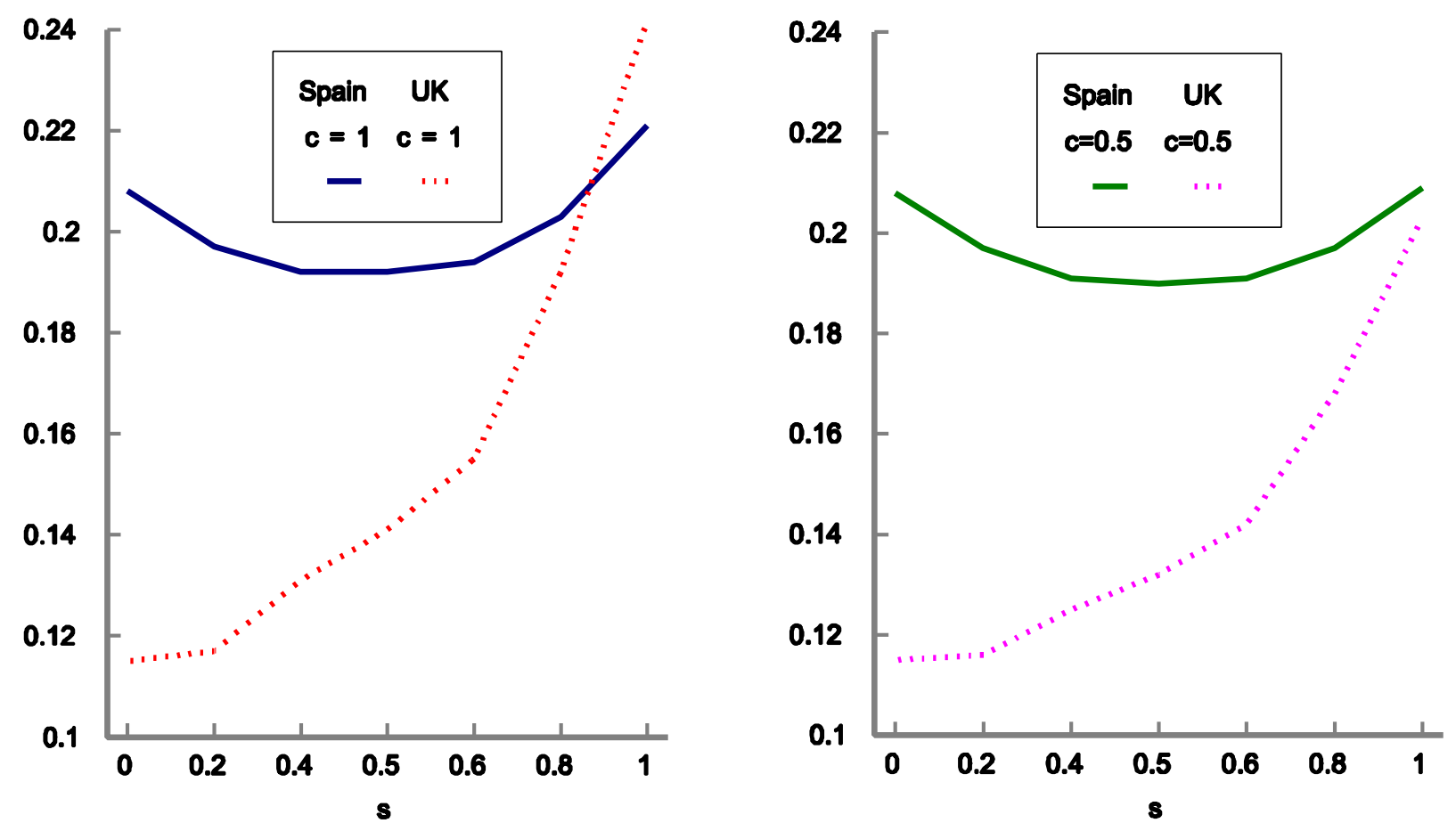

Figure 1: Inequality profiles $I_{\mathrm{E}}$ for two values of child weight $c$.

\section{Conclusion}

Equivalence scales play a central role in the analysis of inequality and social welfare: they do the job of quantifying individual welfare levels in a comparable fashion. Although one might seek to base such comparability upon a coherent microeconomic principles, and use sophisticated econometric techniques to do so, it is fanciful to suppose that equivalence scales can be constructed without the introduction fundamental value judgements.

The choice of a particular equivalence scale allows one to quantify the exact differences between welfare levels of those with different level of needs, but given the value judgement inevitable 
implicit in any equivalence scale, it may be more appropriate to recognise that value judgements may differ when measuring income inequality and social welfare, in the same way this is done in other areas of measurement. In this respect the two alternative approaches discussed here - AtkinsonBourguignon sequential dominance, and dominance with respect to a parametric class of equivalence scales - have much to offer in terms of practical insights on practical problems of distributional comparison in the presence of household diversity. As we have seen in the UK-Spanish comparison of section 5, not only relative differences between countries, but also distributional ranking can be very sensitive to the choice of equivalence-scale parameters that reflect sensitivity to the size and composition of households.

Finally we should draw attention to two gaps that have been left open. First, our discussion has deliberately focused upon the equivalence scale framework to household differences; other recent approaches - based on the so-called collective model of household behaviour - attempt to bypass the use of an equivalence scale by modelling individual welfare directly and recovering information about "who gets what" from household micro-data. Second we have left untouched a profound question about the nature of "need". In common with most of the literature we have assumed that the meaning of this concept has been well defined and that the essential question is simply how to incorporate it in inequality and welfare comparisons. But the more basic questions remain: which economic or social variables determine need, and how? Can "need" be effectively distinguished from "choice"? Such questions are the subject for substantial research programmes in their own right. 


\section{References}

Apps, P. F. (1994) "Female labour supply, house work and family welfare", in Blundell, R., Preston, I. and Walker, I. (eds) The Measurement of Household Welfare, Cambridge University Press, Cambridge, pp. 140163

Apps, P. F. and Savage, E. J. (1989) "Labour supply, welfare rankings and the measurement of inequality", Journal of Public Economics, 39, 335-364

Atkinson, A.B. (1970), "On the measurement of inequality", Journal of Economic Theory, 2, 244-263.

Atkinson, A. B., (1992) "Measuring poverty and differences in family composition" , Economica, 59, $1-16$.

Atkinson, A. B., and Bourguignon, F. (1987) "Income distribution and differences in needs - In Feiwel, G.R. (editor) Arrow and the Foundations of the Theory of Economic Policy - Macmillan, New York., pp 350-371

Atkinson, A. B., Gardiner, K., Lechêne, V. and Sutherland, H. (1993a), "Comparing low incomes in France and the United Kingdom: evidence from household expenditure surveys", Microsimulation Unit Discussion Paper Series, 1, Department of Applied Economics, Cambridge.

Atkinson, A. B., Gardiner, K., Lechêne, V. and Sutherland, H. (1993b), "Comparing poverty in France and the United Kingdom", Welfare State Programme Discussion Paper WSP/84, STICERD, London School of Economics.

Banks, J. and Johnson, P. (1994) "Equivalence scle relativities revisited", Economic Journal, 104, 883890

Barten, A. (1964), "Family composition prices and expenditure patterns", in Hart, P. et al. (eds) Econometric Analysis for National Economic Planning, 16th Symposium of the Colston Society. Butterworth, London

Blackorby, C. and Donaldson, D. (1991) "Adult equivalence scales, interpersonal comparisons of wellbeing, and applied welfare economics", in Elster, J. and Roemer, J. (eds.) Interpersonal Comparisons and Distributive Justice, Cambridge University Press, Cambridge.

Blackorby, C. and Donaldson, D. (1993) "Adult equivalence scales, and the economic implementation of interpersonal comparisons of well-being", Social Choice and Welfare, 10, 335-361. 
Blundell, R. W. (1994) "Equivalence scales and welfare", in Jenkins, S.P. Kapteyn, A. and van Praag, B. (eds) Distribution of Welfare and Household Production: An International Perspective, Cambridge University Press.

Blundell, R. W. and Lewbel, A. (1991) "The information content of equivalence scales", Journal of Econometrics, 50, 49-68

Bosch, A. (1990) "Economies of scale, location, age, and sex discrimination in household demand", European Economic Review, 35, 1689-1595.

Bourguignon, F. (1993) "Individus, familles , bien-être social", Document nº 93-24, DELTA, Paris

Buhmann, B., Rainwater, L., Schmaus, G. and Smeeding, T. (1988) "Equivalence scales, well-Being, inequality and poverty: Sensitive Estimates across ten countries using the Luxembourg Income Study (LIS) database", The Review of Income and Wealth, 34, 115-142.

Coulter, F. A. E., Cowell, F. A. and Jenkins, S. P. (1992a) "Differences in needs and assessment of income distributions", Bulletin of Economic Research, 44, 77-124

Coulter, F. A. E., Cowell, F. A. and Jenkins, S. P. (1992b) "Equivalence scale relativities and the extent of inequality and poverty", Economic Journal, 102, 1067-1082.

Cowell, F. A. (1984), "The structure of American income inequality", Review of Income and Wealth, 30, 351-375.

Cowell, F. A. (1995), Measuring Inequality, (2nd Edn) Harvester Wheatsheaf, Hemel Hempstead.

Cutler, D. and Katz, L. (1992) "Rising inequality? Changes in the distribution of income and consumption in the 1980s", American Economic Review, Papers and Proceeedings, 82, 546551.

Danziger, S. and Taussig, M.K. (1979), "The income unit and the anatomy of income distribution", Review of Income and Wealth, 25, 365-375.

Deaton, A. S. and Muellbauer, J. N. J. (1986), "On measuring child costs: with applications to poor countries' Journal of Political Economy, 94, 720-744.

Duclos, J.-Y. and Mercader, M. (1994) "Household composition and classes of equivalence scales: with application to Spain and the UK", Microsimulation Unit Discussion Paper MU 94-03, Department of Applied Economics, Cambridge.

Ebert, U. (1995), "Income inequality and differences in household size", Mathematical Social Sciences, 30, 37-55. 
Ebert, U. (1996), "Social Welfare when needs differ", Economica, 63, forthcoming.

Fisher, F. M. (1987) "Household equivalence scales and interpersonal comparisons", Review of Economic Studies, 54, 519-524.

Glewwe, P. (1991), "Household equivalence scales and the measurement of inequality: Transfers from the poor to the rich could decrease inequality", Journal of Public Economics, 44, 211-216.

Hugounenq, R., and Sastre-Descals, J. (1991), "Effets redistributifs de la contribution sociale generalisée", Économie et Prévision, 98.

Hugounenq, R., and Sastre-Descals, J. (1993), "Quelques reflexions pour une simplification de l'IRP"', Économie et Prévision, 110-111.

Jenkins, S. P. and Cowell, F. A. (1994) "Parametric equivalence scales and scale relativities", Economic Journal, 104, 891-900.

Jenkins, S. P. and Lambert, P. J. (1993), "Ranking income distributions when needs differ", Review of Income and Wealth, 39, 337-356

Kolm, S.-Ch. (1969), "The optimal production of social justice", in Margolis, J. and Guitton, H. (eds), Public Economics, Macmillan, London.

Kolm, S.-Ch. (1976a) "Unequal inequalities I", Journal of Economic Theory, 12, 416-442.

Kolm, S.-Ch. (1976b) "Unequal inequalities II", Journal of Economic Theory, 13, 82-111.

Lanjouw, P. and Ravallion, M. (1995) "Poverty and household size", Economic Journal, 105, 14151434

Lewbel, A. (1989) "Household equivalence cales and welfare comparisons", Journal of Public Economics,39,377-391.

Mercader, M. (1993) "The low income population in Spain, and a comparison with France and the UK: Evidence from the household expenditure surveys", Welfare State Programme Discussion Paper WSP/95, STICERD, London School of Economics.

Muellbauer, J. (1974), "Household composition, Engel curves and welfare comparison between households", European Economic Review, 5, 103-122.

Murthi, M. (1994) "Engel equivalence scales in Sri Lanka: exactness, specification and measurement error", in Blundell, R., Preston, I. and Walker, I. (eds) The Measurement of Household 
Welfare, Cambridge University Press, Cambridge, pp. 164-191

Pollak, R. A. and Wales, T. J. (1979) "Welfare comparisons and equivalence scales", American Economic Review, 69,216-221.

Rainwater, L., (1994) "Family equivalence as a social construction", in Ekert-Jaffe, O. (editor), Standards of Living and Families: Observations and Analysis, John Libby Eurotext, pp. 23-39.

Ringen, S. (1991), "Households, standards of living and inequality", Review of Income and Wealth, 37, $1-13$.

Rodrigues, C. (1993), "Mesurement and decomposition of inequality in Portugal 1980/81 - 1989/90", University of Cambridge, Department of Applied Economics, Microsimulation Unit Discussion Paper, MU93/02

Sen, A.K. (1973), On Economic Inequality, Oxford University Press, London.

Shorrocks, A. F. (1983), "Ranking income distribution", Economica, 50, 3-17.

Shorrocks, A. F. (1995), "Income and Welfare Evaluation of Heterogeneous Income distributions", University of Essex, Department of Economics, Discussion Paper 447. 